\title{
Conhecendo deuses, doenças de branco e fezes de gavião-real: notas sobre a matriz classificatória de bichos-de-pena entre os Kujubim em Rondônia
}

\author{
GABRIEL SANCHEZ \\ Universidade Federal de São Carlos, São Carlos, São Paulo, Brasil \\ sanchezg94@gmail.com
}

DOI 10.11606/issn.2316-9133.v29i2pe157264

resumo $O$ presente artigo diz respeito aos conhecimentos sobre os seres que nossa ciência biológica classifica como "aves" entre os Kujubim (Rondônia), a partir de suas práticas e perspectivas intelectuais, materiais e semióticas. Sendo assim, partindo das relações entre bichos-de-pena e os Kujubim, pretendo demonstrar como opera uma matriz classificatória entre o grupo, isto é, as operações intelectuais e práticas envolvidas nestas "classificações", explorando como o conhecimento desses seres se constitui, se adquire e os organiza em determinadas categorias. Neste sentido, através do modo como os Kujubim se relacionam com as "aves", pretendo contribuir para os "estudos animais" partindo da seguinte questão: o que a análise do "sistema" de classificação dos Kujubim acerca das "aves" revela sobre as relações semióticas entre humanos e animais? E, ainda, o que essas relações podem nos revelar sobre os aspectos das próprias classificações e como elas se fundamentam?

palavras-chave Kujubim. Rondônia. Etnologia Indígena. Relações humanoanimal. Conhecimento.

Meeting gods, white people's disease and hawk stool: on classificatory aspects of feathers animals among the Kujubim from Rondônia, Brazil

abstract The article concerns the knowledge about the beings that our biological science classifies as "birds" among the Kujubim (Rondônia), from their practices and intellectual, material and semiotic perspectives. Thus, starting from the relations between bichos-de-pena (feathers animals) and the Kujubim, I demonstrate how a classificatory matrix operates between the group, that is, the intellectual and practical operations involved in these "classifications". In doing so I explore how the knowledge about these beings is constituted, acquired, and organized into certain categories. In this sense, through the way the Kujubim relate to "birds", I intend to contribute to animal studies on the following 
question: what the analysis of the "classification system" of the Kujubim about "birds" reveals near the semiotic relations between humans and animals? And yet, what can these relations tell us about the aspects of the classifications themselves and how they are substantiated?

keywords Kujubim; Rondônia; Indigenous Ethnology; Human-animal relations; Knowledge

\section{Conociendo dioses, enfermedades de los mestizos y caca de halcón: aspectos}

\section{clasificatorios de bichos-de-pena entre los Kujubim de Rondônia, Brasil}

resumen $\mathrm{El}$ artículo reflexiona sobre los conocimientos sobre los seres que la ciencia biológica occidental clasifica como "aves" entre los Kujubim de Rondônia, Brasil. Lo hacemos eso desde las prácticas y perspectivas intelectuales, materiales y semióticas Kajubim. Siendo así, partiendo de las relaciones entre bichos-de-pena (animales de plumas) y los Kujubim, pretendo demostrar cómo opera una matriz clasificatoria entre el grupo, es decir, las operaciones intelectuales y prácticas involucradas en estas "clasificaciones", explorando cómo el conocimiento de esos seres se constituye, se adquiere y los organiza en determinadas categorías. En este sentido, a través del modo como los Kujubim se relacionan con las "aves", pretendo contribuir a los estudios animales basado en la siguiente cuestión: ¿lo que el análisis del "sistema" de clasificación de los Kujubim acerca de las "aves" revela sobre las relaciones semióticas entre humanos y animales?, y, ¿qué estas relaciones pueden revelarnos sobre los aspectos de las propias clasificaciones y cómo se basan?

\section{Introdução}

Era um daqueles como poucos dias na Amazônia em que os incessantes ventos protagonizavam as temidas friagens na Baía das Onças. Isso, segundo os Kujubim, explica o fato de as águas começarem a baixar e a Baía revelar suas pedras com o escoamento da água rumo ao rio. Sentados em volta de uma pequena fogueira estávamos eu e Manduca, acompanhados dos longos soluços resultantes da chichada que ocorrera durante o dia. Manduca me perguntou se eu havia gostado da carne do rabo do jacaré que eles haviam caçado e assado para o almoço. Respondi, saciado, que sim. Ele então diz, sarcasticamente, que o povo lá de Sagarana não comem jacarés, “pois jacarés são deuses para eles”. Fascinado e ao mesmo tempo intrigado com aquela afirmação, perguntei para Manduca se os Kujubim também não comiam algum animal que também fosse um deus. E logo ele me responde: ah, tem sim, os cujubim.

Manduca então começou. "No tempo da maloca - essa é a fórmula regional para se contar qualquer história - o sol baixava três vezes do dia e nesse tempo o deus aparece para entregar o espírito de quem nasceu ou de levar embora o de quem morreu. E os bicho-depena do dia, galo capim, bem-te-vi, coruja não, bico de brasa... aparecem pra elogiar e fazer 
manifestação pra receber o deus e o espírito. O cujubim aparece na manifestação porque na verdade é ele que leva e traz os espíritos da gente pra dentro ou fora do corpo, então o cujubim é deus porque ele vinha em forma de bicho-de-pena. E é por isso que os antigos não comiam cujubim, a gente criava eles, eles podia andar dentro da maloca, mas também tinha muito, muito, muito, e então eles andava no igarapé também, era muito”.

A cena descrita na passagem que inaugura o texto é resultado de uma pesquisa de campo de seis meses com os Kujubim. ${ }^{1}$ Dentro do tema das relações avi-humanas, o presente artigo insere-se no debate concernente às inter-relações entre humanos e animais - em específico, as "aves" - em vários de seus desdobramentos (DESCOLA 1992; 1998; INGOLD 1994; VANDER VELDEN 2012; 2015). Mediante a isso, este artigo é fruto de uma etnografia multiespécie (KIRKSEY; HELMREICH, 2010) sobre os conhecimentos e as práticas efetivas acerca dos seres que nossa ciência biológica classifica como "aves" a partir das perspectivas intelectuais, materiais e simbólico-semióticas - dos Kujubim.

Muitos povos indígenas que se encontram na área denominada como Grande Rondônia (VANDER VELDEN 2010) ainda são pouquíssimos estudados e mesmo conhecidos. Os Kujubim constituem um desses tantos grupos que vivem no sudoeste amazônico, no estado de Rondônia, fronteira com a Bolívia, cuja língua - Kuyubi ou Kaw tawo - pertence à família linguística Txapakura. Apesar de terem sido considerados extintos pelo estado brasileiro nos anos 1980, os Kujubim vêm retomando seu protagonismo no cenário regional e nacional desde a década de 2000, principalmente no que tange à demarcação de seu território tradicional e à reivindicação de direitos constitucionais; entretanto, do ponto de vista deles próprios e de outros povos da região, eles nunca deixaram de existir e de resistir.

Na Terra Indígena (T.I.) do Rio Guaporé, onde vivem os Kujubim, estão situadas seis aldeias próximas umas das outras, e é conhecida pela sua complexa diversidade multiétnica e multilinguística. Atualmente, dez etnias compõem a diversidade da T.I., divididas em seis famílias linguísticas. ${ }^{2}$ Uma intensa rede de trocas fundamenta a complexa constituição da organização e das relações sociais entre os moradores de diversas etnias naquela região. Além, evidentemente, das pessoas terem de compartilhar uma experiência rotineira, casar e conviver com outras etnias e línguas, a complexa configuração sociopolítica proporciona um quadro de sucessivas trocas - ainda que inconscientes, e indiretamente que fundamentam esse tipo de organização social (MALDI 1991; SOARES-PINTO 2009;

\footnotetext{
${ }^{1} \mathrm{O}$ trabalho de campo foi dividido em um período de seis meses ao longo de dois anos: de março a julho de 2018 e junho e julho de 2019.

${ }^{2}$ As etnias que vivem na T.I são: Aikanã, Aruá, Arikapú, Djeorometxi, Kanoé, Kujubim, Makurap, Tupari, Wajuru e Wari'. As famílias linguísticas correspondem à: Aikanã, Jaboti, Kanoé, Mondé, Tupari e Txapakura.
} 
2014): trocas de cônjuges, substâncias, elementos da cultura material, de histórias, mitos e, o que interessa a esse texto, os conhecimentos sobre animais, em específico, as “aves".

Neste sentido, pretendo, através do modo como os Kujubim se relacionam com as "aves", contribuir para os estudos animais (DEMELLO 2012; BEVILAQUA; VANDER VELDEN 2016) partindo da seguinte questão: o que a análise dos "sistemas" de classificação dos povos indígenas das terras baixas da América do Sul - e aqui em específico, as “classificações” dos Kujubim acerca das “aves” - revelam sobre as relações práticas, semióticas e materiais entre humanos e animais? E, ainda, o que essas relações podem nos revelar sobre os aspectos das próprias "classificações" e como elas se fundamentam? Sendo assim, interessa investigar as "classificações" na prática, tendo-se em mente que nenhuma precede a outra, e que ambas emergem sempre juntas, numa espécie de dialética permanente entre teoria e prática, sentido e materialidade.

Note-se, todavia, que os Kujubim jamais falam ou fazem referência a categoria biológica de "ave". Como poderíamos, então, partir de uma categoria que sequer existe entre os Kujubim, para assim compreendermos o modo como se constitui um "sistema" de "classificação"? Há dois caminhos para responder a essa questão: o primeiro, é de que os estudos etno-classificatórios (BERLIN 1992; CARRARA 1997) apontam para o fato de que uma gama de seres pode ser reconhecida sem que exista uma palavra específica para definir categorias genéricas como as de "planta", "animais" e "aves". O segundo, é pressupor que existe uma diferença que impele a própria relação entre o conceito de "ave" e o conceito Kujubim de bicho-de-pena, estabelecendo assim, uma espécie de equívoco (VIVEIROS DE CASTRO 2004). Tais caminhos não são opostos, mas, antes, parecem nos guiar de modo dialético: "aves" e bichos-de-pena tem em comum o fato de possuírem seus corpos cobertos por penas - fato relativamente comum como nos apontam os estudos em folktaxomy. Mas, também, constituem uma relação de diferença na medida em que, por meio de relações de diversas ordens (sejam intelectuais ou práticas), aos bichos-de-pena são atribuídos estatutos que fazem deles muitas coisas que não "aves".

Além disso, como veremos, ao que me refiro como "classificação", não parece ser simplesmente uma ação de organizar o mundo de forma pragmática para os Kujubim. Afinal, seria uma "classificação" um conjunto tão heterogêneo de relações, como estes sugerem, para definir e organizar os seres? Há uma grade finita de critérios de "classificação" que compõem um "sistema"? Nesse sentido, procuro pensar as "classificações" Kujubim, a partir da ideia de matriz classificatória de atributos e relações variados: os Kujubim levam em conta diversas relações (que poderíamos denominar ecológicas e interespecíficas) que os bichos-de-pena estabelecem no mundo para pensá-los sob categorias e termos. Por exemplo: bichos-depena que vivem nas beiras dos rios, ou nos rios se alimentam, são ditos do rio. Acontece, todavia, que como nos havia alertado Joana Cabral de Oliveira (2006), existem diferentes "formas classificatórias" que extrapolam a ideia de organização hierárquica, e isso parece ser 
também concebido para os Kujubim: a categoria "do rio" não é hierarquizada dentro de um sistema, tampouco os bichos-de-pena o são.

Os seres não são definidos em categorias, mas, antes, nas relações entre "classes de posições", isto é, a posição dos termos no pensamento Kujubim, e entre "classes de relações", as relações empíricas que os seres tecem e produzem no mundo. Desta forma, os seres não são condicionados (no sentido de uma condição) à uma categoria: eles transitam por elas, a depender do contexto e das relações que eles produzem empiricamente ou que os Kujubim fazem de forma intelectual, mas sempre a partir do contato com o mundo. Tais relações entre classes são a engrenagem de uma "máquina" que geram matrizes classificatórias de atributos variados, termos e critérios que sofrem a todo momento transformações, mudanças, transições, por sempre depender de contextos relacionais e de relações empíricas.

Sendo assim, tais princípios desse "sistema" de conhecimento parecem funcionar numa espécie de dialética entre intelectualismo e empiricismo, na medida em que toda "classificação", que é uma ação eminentemente intelectual, se mostra de certa forma dependente de ações práticas de socialidade com outros seres, que é o que hipoteticamente fundamenta e sustenta essas relações e ao mesmo tempo age na forma de "classificar". As "classificações" Kujubim são constituídas no interior de uma matriz classificatória e de conhecimento que congrega diversos níveis da vida do grupo: concepções cosmológicas, a minuciosidade da observação dos comportamentos, dos traços morfológicos, interesses práticos, a percepção sensorial, a forma como as relações sociais são tecidas e que, no limite, dizem respeito às práticas e às operações intelectuais de uma forma geral sobre o modo como o mundo e os seres que vivem nele são experienciados, apreendidos e inteligíveis.

Ao defender a ideia de "matriz classificatória", pretendo mostrar como certas categorias nativas - vide bichos-de-pena, qualidade, bicho, parente - acabam por ser fundamentais no modo como são tecidas certas relações em um amplo socius aberto para diversos seres: animais, espíritos, donos. Essas categorias devem ser levadas em conta principalmente por uma questão epistemológica, tendo em vista que certas categorias como a de animal, planta, ave, espécie e a própria classificação - podem encontrar, mas não necessariamente encontram um correspondente no pensamento Kujubim, que, por sua vez, implicam na extrema dificuldade em correlacionar categorias científicas e indígenas. ${ }^{3}$ Principal exemplo disso é partir da categoria "ave" para se realizar a pesquisa, sendo que ela não encontra um correspondente no pensamento Kujubim, pois lá esses seres parecem

\footnotetext{
${ }^{3}$ Neste sentido, tentarei, sempre que possível, ter o máximo de cuidado metodológico quando essas correlações aparecerem. Evitá-las é importante, pois, como argumenta Lévi-Strauss (2005), os recortes do real por diversos grupos indígenas não correspondem necessariamente aos recortes feitos pela biologia ocidental, tendo em vista que distintos coletivos podem acessar o real apenas de forma parcial, nunca total. Para resolver essa questão, pelo menos no que tange à exposição textual, categorias como ave, espécie, natureza, vegetal, entre outras, aparecerão entre aspas ao longo do texto. Toda categoria propriamente Kujubim aparecerá ao longo do texto em itálico.
} 
escapar a uma designação categórica e um recorte que os enquadre em uma definição precisa, tal como temos na biologia moderna, pois como apontam os estudos em etno-biologia e taxonomina folk, as categorias indígenas reconhecem outros tipos de relações que as constituem (FARIA; ALVES 2007; BERLIN 1992). Entre os Kujubim o que "existe" não necessariamente são "aves", mas deuses, doenças de branco, fezes de gavião-real. Estes seres são os bichos-de-pena.

\section{Os Kujubim e o "sistema regional"}

Do ponto de vista antropológico e etnológico, cabe dizer que até o presente momento nenhum esforço havia sido feito para descrever os Kujubim. Parte do esforço deste artigo é também apresentar aos leitores alguns aspectos sobre este povo ainda pouquíssimo estudado e conhecido na etnologia americanista.

Há indícios documentais - como mapas, relatórios e diários - mas também informações coletadas por mim de uma matriarca Kujubim que foi capturada por seringueiros na década de 1940, de que os atuais Kujubim eram, na verdade, três grupos distintos, que falavam a mesma língua, apresentando algumas variações dialetais e que operavam diversas trocas de cônjuges, alimentos e artefatos. Os nomes de tais grupos eram Kumaná, Matawá e Kujona. Embora apresentassem algumas diferenças, por ocuparem o mesmo território, os não-índios da época os chamavam indistintamente de "Cautários", muito provavelmente pela interpretação que fizeram de um termo que ouviram dos Moré, grupo com relações históricas com o Kujubim, que atribuíam a esses últimos o nome "kaw tayo", que significa "comedores de peixe-cachorro".

$\mathrm{Na}$ ata da "I Assembleia do Povo Kujubim", realizada em 2002, consta a informação, proveniente das matriarcas já falecidas Suzana, Rosa e Francisca, mulheres que viveram diretamente no território tradicional dos Kujubim e que possuem um papel fundamental na retomada do território do coletivo, que o nome do grupo foi dado pelos integrantes da comitiva de Marechal Rondon, que passou pelo território por volta dos anos de 1920 e atribuiu-lhes esse nome devido ao fato de que moravam em um igarapé onde havia abundância do cujubim, um bicho-de-pena. Nos dias atuais, Kujubim é a forma pela qual todos os indivíduos do grupo e mesmo os que não fazem parte dele identificam a etnia.

A língua Kujubim pertence à família linguística Txapakura e foi classificada por Duran (2000) como 'Kuyubi' ou 'Kaw tayo'. As últimas falantes da língua Kuyubi das quais se teve notícias, e com as quais ainda se puderam realizar estudos linguísticos mais recentes, foram as três matriarcas que, infelizmente, já faleceram. Nos dias atuais, a comunicação oral na língua se reduz a algumas palavras do uso cotidiano como chicha (tok ta) - bebida fermentada de mandioca - e os nomes de alguns animais presentes no cotidiano, por exemplo, a anta (imin), o queixada (miyak) e a onça (kinam), sendo o português a língua predominantemente falada. 
Os Kujubim estão distribuídos por todo o estado de Rondônia, com maior concentração de pessoas nas regiões sudoeste e sul do estado, na divisa com a Bolívia. Eles residem, especialmente, em duas aldeias - Baía das Onças e Posto Indígena Ricardo Franco - localizadas na T.I do rio Guaporé, situada no município de Guajará-Mirim. A dispersão do grupo se deu, sobretudo, a partir do contato com os não-índios que se intensificou no final dos anos 1920, quando a região passou a ser ocupada por pessoas ligadas à extração do caucho e da borracha (MALDI 1991). Os Kujubim tiveram seu território tradicional - localizado no rio Cautário, afluente do Guaporé - invadido e grande parte da população, como disse Suzana, umas das matriarcas que viveu no território, acabou morrendo por conta de doenças. Alguns Kujubim que sobreviveram a esses contatos iniciais conseguiram fugir para outras regiões, mas outros, no entanto, que não morreram por conta das doenças, foram capturados por seringueiros e levados para os barracões de seringa de diferentes lugares, principalmente para Canindé, Esperança, Marçal, Ouro Fino e Santa Lurdes. Foi aí que teve início a dispersão dos Kujubim por Rondônia, tal como aconteceu com vários grupos nativos do vale do Guaporé (MALDI 1991).

Quando os Kujubim foram expulsos de seu território tradicional ${ }^{4}$ e aqueles que sobreviveram às doenças dos brancos foram levados para trabalhar forçadamente na extração da seringa, após alguns anos, com a criação do Posto Indígena Ricardo Franco, diversas etnias, assim como os Kujubim, foram conviver de modo conjunto na T.I Guaporé. O convívio diário e os casamentos interétnicos entre diversas etnias proporcionam, até os dias de hoje, os cruzamentos de práticas, técnicas, saberes e da cultura material e intelectual, que, por sua vez, recaem na categoria parente, que, etnograficamente, corresponde a uma ideia que não se restringe simplesmente a uma parentela, mas, antes, a potenciais relações que se pode estabelecer através do casamento e, principalmente através do convívio: ser parente é conviver, é dançar junto, cantar, beber, caçar, contar histórias e observar o mundo conjuntamente.

Metodologicamente, para analisar e descrever às nuances e relações que constituem o complexo cenário etnográfico e que provisoriamente chamo de "sistema regional", apoiome no conceito de rede (LATOUR 1994), mas que ganha contornos específicos ao ser tratado por Gallois (2005) na região das Guianas: "a noção de rede permite apreender espaços de mediação e de tradução entre esferas normalmente tomadas como separadas” (GALLOIS 2005: 14). Utilizar o conceito de rede, então, acaba por ampliar a possibilidade analítica dos tipos de relações que estão envolvidas ali, deslocando a ideia de que elas são reduzidas e restritas às contraposições culturais ou étnicas.

Como lidar com o fato de, ao perguntar para um Kujubim a respeito do socó-boi, ele me responder sobre como, supostamente, os Wajuru pensam esse bicho-de-pena? Será que

\footnotetext{
${ }^{4}$ Atualmente, o território tradicional dos Kujubim está em processo de identificação e deverá, futuramente, constituir a T.I do Rio Cautário.
} 
é possível fazer uma separação de práticas e de conhecimento a partir de pessoas que vivem cotidianamente juntas e, portanto, são parentes? Ou que todos os grupos da região possuem línguas diferentes, mas todos se referem aos não-índios pelo termo eré, da língua Djeorometxi? Ou, ainda, que nenhuma etnia, a não ser os Kujubim, comiam bichos-decasco, isto é, tracajás e outros quelônios, e agora elas são uma iguaria nobre dentro dessa rede e todos passaram a comê-la?

Nesse sentido, utilizando a ideia de rede, o que importa, afinal, é ver como essas negociações são feitas pelos próprios índios, como eles constituem essas relações, e de que maneira, eles acabam negociando o exterior e o interior de uma maneira propriamente criativa e pertencente a ninguém mais do que eles próprios; e, assim, se é possível falar em exterior e interior quando "a alteridade é uma relação interna, onde o eu é, antes de mais nada, uma figura do outro" (VIVEIROS DE CASTRO 2002: 430).

Em meio a esse cenário, parto da perspectiva Kujubim dentro desse sistema regional. Os dados que estão na pesquisa e, neste texto, são também dados regionais, mas são regionais, antes de tudo, da perspectiva dos próprios Kujubim.

\section{As relações Kujubim: socius, cosmos, donos e almas animais}

Para compreender os conhecimentos sobre e as "classificações" dos seres que nossa ciência biológica apreende como "aves", segundo o modo como opera o pensamento Kujubim, é necessário que se atente para as diversas relações que são estabelecidas não somente entre seres humanos e animais, mas também os pressupostos que sustentam esses tipos de relações e que se desdobram na socialidade produzida entre os seres. $\mathrm{O}$ agenciamento das relações se revela por meio das interações das "espécies" animais, espíritos, donos e que são homologas, como veremos, às formas como os próprios Kujubim se relacionam com o mundo e com os seres.

As relações dos Kujubim são concebidas a partir da socialidade entre humanos e não humanos através de inúmeras práticas cotidianas que possibilitam que essas relações cofundamentem as "classificações" intelectuais de bichos-de-pena; isto é, elas são simultâneas às próprias "classificações": para entender como se "classifica" um bicho-de-pena, é necessário conhecê-lo, como "funciona" sua alma, que por sua vez se desdobra em comportamentos, costumes e afecções, sua cultura, seu espírito-dono. Mas também é necessário, sobretudo, relacionar-se com ele: é necessário caçá-lo, comê-lo, criá-lo, contar histórias sobre ele. Pois note-se que toda "classificação", que é uma ação eminentemente intelectual, se mostra de certa forma dependente de ações práticas de socialidade com outros seres, que é o que fundamenta e sustenta essas relações. Sendo assim, uma espécie de dialética entre intelecto e prática, epistemologia e ontologia, intelectualismo e empiricismo guia a forma como uma "classificação" é fundamentada e o conhecimento sobre bichos-de-pena é 
constituído entre os Kujubim, pois essas são dimensões inseparáveis que se atualizam mutuamente.

Vejamos em um relato de Doca Kujubim, o modo como ele aprendeu sobre bichosde-pena, seus nomes e seus comportamentos:

Quando a gente era mais novo, os velhos daqui levavam a gente pra andar no mato...saía cedo daqui. Ia o Raimundo, Pororoca, Alonso [pajés] e enquanto a gente andava eles iam falando: olha lá aquele é tal bicho e aquele é outro. Contavam história sobre os bichos, ensinava a arremendar, falava o que gostava de comer, onde dormia e era assim, fazia tudo junto.

Nesse relato etnográfico podemos perceber que não é possível separar a forma como o conhecimento (intelectual e prático) - e a "classificação" - são adquiridos. Doca nos sugere que o conhecimento sobre bichos-de-pena foi adquirido a partir do que os antigos ensinaram, mas, simultaneamente, foi experienciado e, portanto, feito na prática a partir de incursões coletivas à floresta. Além disso, em outro nível, as relações práticas dos próprios bichos-de-pena, como veremos, acabam por organizar as categorias classificatórias dos Kujubim.

A questão sobre o conhecimento Kujubim também pode ser pensada através de uma analogia com a minha própria experiência metodológica com eles. Este artigo é resultado de uma pesquisa de campo que teve em sua gênese a etnografia multiespécie (KIRKSEY; HELMREICH 2010) como desafio, inspiração e, principalmente, enquanto método. Focalizar os conhecimentos humanos sobre "espécies" "naturais", que fundamentam (e são fundamentados por) diversas relações com "espécies" animais, implica em não somente conhecer esses conhecimentos, mas também entender como eles são apreendidos e quais são as bases que os sustentam em um sistema ainda mais amplo de organização intelectual, de práticas diretas com esses animais e por meio da socialidade entre eles. O ponto fundamental que o método etnográfico multiespécie impõe ao pesquisador é que a realidade etnográfica passa por uma mudança brusca de percepção das relações sociais; no caso desse trabalho, que apreendeu as relações que os Kujubim estabelecem com bichos-de-pena, mas também outros seres não humanos, essas relações são desdobradas em conhecimentos e, precisamente, em "classificações"; isto é, o método etnográfico multiespécie é fundamental para ver a forma como "classificações" são constituídas, pois elas têm em sua fundamentação diversas relações emaranhadas entre seres humanos e não humanos.

As coisas ficam interessantemente mais complicadas quando falamos sobre e a partir dos mundos ameríndios. Dentro do sistema regional do Rio Guaporé, são estabelecidas relações de socialidade com um extenso e amplo socius com os mais diversificados seres. Neste sentido, o que está em jogo não é somente o fato de conhecer e "classificar" um animal, mas, para isso acontecer, também deve-se conhecer o seu espírito e seu espírito dono, a cultura desses seres que implicam diretamente em relações práticas. Qualquer pesquisador 
que busque produzir uma "etnografia multiespécie" deve ficar atento a essas diversas situações e relações e passar a incluir outros tipos de seres, que não somente os humanos, na sua forma de escrever e dentro da própria escrita. É dar protagonismo a esses seres dentro de nossos textos, ainda que não possamos conversar com eles, pois assim fazem os interlocutores da pesquisa etnográfica.

Durante a pesquisa de campo, não etnografei apenas os Kujubim, mas, conjuntamente, os próprios bichos-de-pena. Para conhece-los, realizei atividades corriqueiras que visavam a observação destes seres junto aos Kujubim. Sendo assim, durante alguns dias acompanhava meus interlocutores humanos às incursões nas florestas, roçadas, nos rios, igarapés e roçados. Conforme uma "espécie" era vista, os Kujubim me descreviam os comportamentos do bicho-de-pena, qual era o seu local preferido de alimentação, o que ele gostava de comer, se constitui algum mito e assim por diante. Neste sentido, pude apreender in-loco as maneiras pelas quais os Kujubim conhecem bichos-de-pena, mas, simultaneamente, ver de que forma esses seres se relacionam com o mundo e outras “espécies”. Neste sentido, durante a pesquisa não me limitei apenas a conversas informais ou entrevistas com os Kujubim; também foi necessário conhecer bichos-de-pena a partir das formas como os próprios Kujubim o fazem, afinal, como compreender a "classificação" das ciganas que meus interlocutores julgam ser muito catinguentas, sem passar por um bando no rio e, de fato, sentir o seu cheiro? Ou, ainda, que o uirapuru possui a cantiga mais bela da floresta, sem poder ouvi-lo durante o crepúsculo?

Para começarmos a compreender o modo como operam as "classificações" Kujubim em torno dos bichos-de-pena, devemos tomar nota de um conceito fundamental que as constituem: o de qualidade. Quando os Kujubim se referem a algum ser, dizem que ele constitui uma qualidade de bicho, uma qualidade de planta, uma qualidade de espírito. Existem, por exemplo, quatro qualidades de araras que os Kujubim reconhecem. Contudo, essas qualidades apresentam algumas características que fazem com que elas sejam "classificadas" e, consequentemente, diferenciadas umas das outras. Para os Kujubim, qualidade é uma descontinuidade que pode ser apreendida no mundo prioritariamente através dos costumes e das afecções de determinado ser, levando em conta a quem e ao que ele é relacionado (convive com quem, se alimenta do que, dorme onde, isto é, seus comportamentos). Ao perguntar para um interlocutor as diferenças entre as qualidades arara-canindé e a arara-vermelha, os aspectos morfológicos salientes desses seres não foram ressaltados - e isso não quer dizer que não sejam reconhecidos. ${ }^{5}$ Meu interlocutor

\footnotetext{
${ }^{5}$ A distribuição do conhecimento sobre bichos-de-pena entre os Kujubim não é restrita a figuras de especialistas. Evidentemente, os mais velhos parecem conhecer mais "espécies" e de forma mais aprofundada, fato que não impede que um(a) jovem não possa descrever detalhadamente os comportamentos e costumes de um bicho-de-pena. Além dessas incursões conjuntas com os Kujubim a fim de conhecer seus bichos-de-pena, conversávamos durante o dia, mesmo nas aldeias, sobre estes seres de modo informal. Livros didáticos sobre
} 
privilegiou aquilo que constitui cada qualidade: a primeira prefere viver nas beiras dos rios onde se alimentam de pequenos frutos e ao longo da vida podem mudar parceiros; a segunda, habita preferencialmente as floretas, elegem as castanhas como seu principal alimento e quando encontram um(a) parceiro(a), seguem juntos para o resto da vida.

Levar em conta as relações que os bichos-de-pena constituem no mundo e apreendêlas, é um fator fundamental para pensá-los sob termos e categorias. Neste sentido, as "classificações" acabam por mobilizar questões epistemológicas que dizem respeito ao conhecimento e as formas de tornar o mundo e as relações tecidas nele inteligíveis e organizadas. Em outro nível, contudo, essas mesmas relações acabam movimentando questões ontológicas que implicam em concepções nativas sobre a ideia de almas animais, cultura dos bichos, espíritos que são donos e assim por diante (CABRAL DE OLIVEIRA 2006). Bichos-de-pena, podem ser objetos do conhecimento humano, mas simultaneamente, também o são sujeitos de relações.

Os Kujubim afirmam que todos os seres do cosmos possuem alma, e quando não, eles próprio são almas que, etnograficamente, são chamadas de espíritos. A alma é o que faz todo animal ter vida e "ser um ser vivente" - que possui costumes, comportamentos e age de alguma forma no mundo. Neste sentido, como já nos alertou Lima (2002) para os Yudjá, a alma é um princípio de subjetivação conferindo a todas as qualidades de seres faculdades que são ao mesmo tempo psicológicas, sociológicas e intelectuais, como a consciência de si e de outrem, linguagem, pensamento e socialidade. Neste sentido, podemos dizer que essa concepção Kujubim é uma variação dos fenômenos animistas (DESCOLA 2006) e perspectivistas (VIVEIROS DE CASTRO 2002) que se encontram nas terras baixas da América do Sul.

A alma, dizem os Kujubim, é o que constitui, juntamente do corpo, uma qualidade de ser. Pelo fato da alma ser específica de cada qualidade, ela é também um marcador de diferenças no modo como cada animal vive e vê o mundo. As almas de cada bicho-de-pena, dizem os Kujubim, é o que permite que ele prefira viver em determinados nichos ecológicos, que preferem comer um fruto ou um inseto ao invés de outros ou se "andam junto" de outras qualidades. Sendo assim, uma alma e seus feixes de afecções, que faz um ser, ser vivente, constitui relações no mundo que são apreendidas pelos Kujubim ao nível epistemológico da "classificação"; note-se, todavia, que em outro nível, essas relações são concebidas pelos Kujubim da mesma forma que as suas próprias: assim como os humanos, bichos moram em suas próprias casas, comem seus principais alimentos, "andam junto" de outros e assim por diante. Como me disse uma interlocutora: "bichos também tem cultura, mas a cultura deles". Além disso, há outras entidades no cosmos que impactam diretamente na forma como os Kujubim se relacionam com bichos-de-pena e como eles são pensados sob 
categorias e termos. Refiro-me, aqui, aos donos e a maestria (FAUSTO 2008). Neste sentido, para os Kujubim e demais povos no Guaporé, todos os seres possuem um dono: a água possui um dono, uma sumaúma possui um dono, o céu tem um dono, há um dono geral para as presas de caça, e, no limite, toda qualidade também possui seu dono. As corujinhas-da-noite dizem os Kujubim, são donas das antas e o jacamim é o dono da formiga trucuá. Esse tipo de relação fundamentado pela maestria é também levado em conta quando falamos de "classificação": emergem categorias como as de donos de bichos que implicam em relações não apenas com os bichos-de-pena, mas as que estes também constituem com outros seres. ${ }^{6}$

O que pretendi nessa seção foi demonstrar que, para se chegar até o nível das classificações via operações intelectuais, é necessário que se atente, também, às interações e relações produzidas pelos seres. Embora as classificações pertençam ao domínio da "taxonomia", isto é, referente a uma questão epistemológica pautada em observações, elas não devem ser isoladas de outras formas de vidas e seres, bem como das interações práticas entre eles, de forma que, nesse sentido, correspondem também à uma questão ontológica propriamente dita. Afinal, prática e intelecto se desenrolam simultaneamente em uma relação dialética. "Classificações” oferecem um guia prático para tornar o mundo inteligível e organizado, mas também são constituídas por ações práticas que se estabelece entre humanos e não humanos. Para os Kujubim as classificações não são somente representações e operações mentais a fim de organizar o mundo, mas envolvem sobretudo contextos relacionais e práticos com os seres e os entes.

Para se classificar as araras, por exemplo, é necessário que se proceda a uma metódica observação de seus atos, de seu comportamento, de sua alimentação. Mas é necessário também que se conheça sobre a cultura das araras, sua alma e suas relações no mundo. Nas cosmologias amazônicas, falar de classificação de seres vivos ou dos animais não descreve, em realidade, o que é efetivamente "classificado": não é possível apartar os animais e os seres vivos de outras formas existentes, como os donos, bem como das relações que fazem com que diversos seres interagem entre si.

\section{Um conhecimento prático Kujubim acerca dos bichos-de-pena}

"Classificação", para nós, é o termo que compreende a forma de organizar os seres e as coisas que estão no mundo através de categorias elaboradas dentro de um "sistema

\footnotetext{
${ }^{6}$ A princípio, ao longo do trabalho de campo, pensei existir uma relação de equivalência entre o conceito de qualidade e o de "espécie". Contudo, essa suposta equivalência se desfez quando, conversando com um professor indígena, ele havia me dito que reconhecia o conceito de "espécie" - afinal, o utilizava em suas aulas de ciência nas escolas -, mas não se tratava da mesma coisa que qualidade. Nesse sentido, podemos dizer que diferença entre "espécie" zoológica e qualidade dos Kujubim está na contextualidade, na revelação da relação e não, propriamente, em seres vistos e "classificados" de forma isolada. Neste sentido, qualidade não é uma entidade biológica, mas fruto de relações e interações entre os seres; ela não é "dada”, mas, antes, produzida, confeccionada e constituída por feixes de afecções (VIVEIROS DE CASTRO 1996).
} 
taxonômico". Note-se, contudo, que até aqui o termo "classificação" apareceu sempre entre aspas. O motivo disso se aplica na ideia de que os Kujubim não reconhecem ou não falam sobre este termo, tampouco o que concebemos como "classificação" pode ser estendido até eles. Como veremos, seria uma "classificação" um conjunto tão heterogêneo de relações?

Cabral de Oliveira (2006) já havia nos alertados sobre os perigos que circunscreve a ideia de "sistema taxonômico". Substituindo tal termo e as concepções que ele carrega consigo, a autora aposta na ideia de "formas classificatórias". Um "sistema taxonômico" carrega "em si uma concepção de organização hierárquica que não é absoluta, mas apenas uma das formas possíveis de organizar os saberes (CABRAL DE OLIVEIRA 2006: 262), e, neste sentido, as "formas classificatórias" envolvem e suportam simultaneamente, aspectos hierárquicos, cosmológicos, morfológicos e assim por diante (Idem: 264).

Até aqui, vimos que as "classificações" Kujubim mobilizam dois aspectos que agem de forma dialética, seja na forma como um conhecimento é adquirido, ou no modo como um bicho-de-pena é concebido: uma epistemologia relacionada inerentemente às interações práticas e, portanto, ontológicas, que não envolvem somente organizações intelectuais categóricas, mas, simultaneamente, relações efetivas que compreendem outros aspectos da vida e dos seres. Neste sentido, procuro pensar a isso que chamamos de "classificação" entre os Kujubim como uma "matriz classificatória". Um bicho-de-pena não é condicionado a uma classe, uma categoria ou um agrupamento, mas, antes, ele transita entre categorias de atributos que são pensadas sobre suas relações no mundo e que são conhecidas contextualmente pelos Kujubim. Sendo assim, enquanto a "classificação taxonômica" organiza os seres de forma pragmática - geralmente associado a traços morfológicos -, uma "matriz classificatória" implica na ideia de que atributos, categorias e relações estão sempre se transformando - e não no sentido atribuído a metamorfose, mas aquele que diz respeito a estados, contextos. É como se o conhecimento prático Kujubim fosse uma máquina que gerasse a todo momento transformações intrínsecas às relações empíricas dos seres e suas próprias (a isso chamamos de classes de relações) e relações entre termos intelectuais (denominado como classes de posições). Aqui, portanto, temos uma tríade de relações que constituem uma matriz: relações entre categorias, relações práticas e a própria relação entre "classes de posições" e "classes de relações".

Antes de avançarmos, talvez seja importante elucidar uma questão: como, então, podemos ver a maneira como os Kujubim "classificam" "aves", se até aqui vimos que não existem categorias como as de "classificação" ou "aves" entre eles? Embora os critérios e formas indígenas de "classificação" possam ser amplamente variados, há de se ressaltar a dificuldade analítica em correlacionar categorias científicas e indígenas. A falta de correspondência entre categorias e termos é amplamente debatida nos estudos de folk 
taxonomy $^{7}$ (BERLIN 1992) e de etno-biologia (POSEY 1987), pois, como já havia sugerido Lévi-Strauss (2005), há sistemas de conhecimento "dos quais faltam termos para exprimir conceitos como os de "arvore e animal", ainda que neles se encontrem nomes necessários para um inventário detalhado de espécies e variedades” (LÉVI-STRAUSS 2005: 15).

Um bom caminho para se pensar a questão é pensar que os termos "classificação" e "matriz classificatória" e, por outro lado, "aves" e bichos-de-pena, estão diante de um equívoco (VIVEIROS DE CASTRO 2004). Para o autor, o equívoco é o que fundamenta a tradução e a relação entre termos distintos, na medida em que a própria relação de diferença os constitui e os impele. Sendo assim, "aves"- mas categorias como as de "espécie" e "classificação" podem ser comparadas e utilizadas para apreender as categorias Kujubim de bicho-de-pena, qualidade e "matriz classificatória" na medida em que elas constituem uma relação de diferença: as relações que constituem uma "ave" para um ornitólogo são diferentes (no sentido de um estado de significação e de práticas) das relações que constituem um bichode-pena para os Kujubim. Note-se, ainda, que não é preciso escolher entre os estudos de taxonomia folk ou estudos que abrangem questões ontológicas como a ideia perspectivista de equívoco: ambos podem auxiliar nos estudos de "classificações" nativas, como bem lembrou Cabral de Oliveira (2006):

Se o perspectivismo e o animismo nos indicam problemas referentes a projeções de conceitos como os de natureza e cultura, por outro lado, a antropologia cognitiva e suas pesquisas sobre taxonomia nativa, por sua vez, problematizam o uso de categorias mais específicas do mundo natural, em especial a de vegetal e animal tomadas como dado no perspectivismo e no animismo. (CABRAL DE OLIVEIRA 2006: 61).

Com essa questão metodológica exposta, sigamos com a "matriz classificatória" dos Kujubim. Na língua Kujubim, embora a palavra que se refira a certos seres seja de pati', cotidianamente eles se referem a eles como bichos. Bicho é um lexema primário para identificar uma série de seres e que, eventualmente, é seguido por um lexema secundário constituído de acordo com traços morfológicos de cada qualidade deles, que acabam por

\footnotetext{
${ }^{7}$ Berlin foi quem estabeleceu alguns princípios para um modelo universal de classificação, tendo em vista que afirmou a existência de categorias universais que podem ser verificados empiricamente, segundo as quais os "povos de tradição oral" e a própria taxonomia cientifica ordenam o chamado "mundo natural”. A perspectiva humana dentro da etno-biologia deve ser compreendida de modo inconsciente em relação à realidade biologia, tendo em vista que, para a taxonomia folk, o mundo natural não pode ser visto como um continuum já que grupos de animais e plantas apresentam eles mesmos a quem observa uma descontinuidade cuja estrutura e conteúdo são vistas pelos seres humanos do mesmo modo, isto é, dados perceptuais que são largadamente imunes a supostas determinantes culturais variáveis, encontrados em outas áreas da experiência humana (BERLIN, 1992: 8).
} 
corresponder aos seus "táxons". Estão os bichos divididos em bicho-de-pena, bicho-de-pelo, bicho-de-casco, bicho-de-asa, bicho-de-couro e peixes.

Poderíamos, por exemplo, pensar que bichos-de-pena correspondem às aves, os bichos-de-pelo aos mamíferos, e assim por diante. Contudo, essa correlação entre as categorias científicas e aquelas Kujubim é muito imprecisa, já que alguns animais que são considerados de uma classe para nós, pertencem a outros táxons segundo a forma como eles são estruturados para os Kujubim. O conhecimento é relacional precisamente porque só se pode apreender parte do real e, por isso, depende do ponto de vista, do que é ouvido ou sentido. Biguás, por exemplo, são bichos-de-pena, pois são cobertos de penas. Contudo, seu comportamento que o constitui enquanto uma qualidade faz com que eles "tendam" aos peixes, pois passam a maior parte do dia dentro da água, mas também por uma questão do gosto que sua carne tem, que se aproxima muito mais a um peixe do que a uma nambu.

No período de trabalho de campo, pude levantar alguns critérios (e eventualmente, subcritérios, ou seja, classes de posições) pelos quais os bichos-de-pena podem ser incluídos: se anda em grupo ou sozinho, alimentação, hábitos, costumes, traços morfológicos, lugar que mora e se alimenta, som, tamanho, originalidade, má-formação, predadores, ariscos, acostumados com o humano, alusões a outras qualidades, dia e noite, bem e mal, profissões, protagonismo mitológico, terrestre, aquático, panema, xingamentos, hierarquia, escatologia, comparações com ações humanas, comestíveis, xerimbabos de humanos, xerimbabos dos outros bichos e bichos-de-pena de pajelança. Contudo, é importante mencionar que há critérios que os Kujubim não nomeiam, ainda que eles sejam reconhecidos, explicitados e utilizados. Por exemplo, alguns bichos-de-pena são reconhecidos a partir da cor de sua carne: preta ou branca. Todavia, os Kujubim não estabelecem um nome para esse critério, ainda que ele seja amplamente reconhecido.

Neste artigo, de todo modo, por falta de espaço, nos debruçaremos em alguns critérios. Uma das "classes de posições" mais importantes para os Kujubim é aquele em que se leva em conta o local de habitação e alimentação dos bichos-de-pena. Aqui, são pensados termos como da água, da terra firme, da floresta, do rio, da praia, do igarapé, do campo, do dia, da noite. Note-se, todavia, que essas "classes de posições" acabam sendo sempre transformadas pelas "classes de relações" dos seres e, por isso, elas nunca são estanques e fixas, mas sempre promovendo transformações através e pelos seres. Mutuns, por exemplo, são ditos do rio, ao mesmo tempo que da floresta, tendo em vista que gostam de se alimentar nas beiras dos rios, mas, ao anoitecer, adentram na mata para dormir.

Outra importante "classe de posição" reserva aos mitos um papel fundamental nas designações classificatórias que podem se desdobrar em outras classes, como se verá a seguir. Os bichos-de-pena que estão inseridos nas narrativas míticas são conhecidos através e ocupam a categoria "têm história". Voltemos, então, a anedota que inaugura esse texto, o "mito" dos cujubins. Cujubins são reconhecidos pelos Kujubim na medida em que eles 
estabelecem algumas relações. Estes últimos sabem dos costumes e comportamentos dos primeiros e, exatamente por isso, permite que ele possa ser pensado sobre categorias e termos. Acontece, todavia, que um cujubim não é, no sentido de uma condição somente um bicho-de-pena, ele ocupa outras categorias que o definem, nas palavras de Manduca Kujubim, como deuses: os cujubins são responsáveis por levar as almas dos humanos para o paraíso celeste. Esse mito sobre esses bichos-de-pena também evoca outros aspectos de classificação quando melhor analisado. Quando Manduca diz - "E os bicho de pena do dia, galo campim, bem-te-vi, coruja não, bico de brasa aparecem pra elogiar e fazer manifestação pra receber o deus e o "espírito" -, ele também diz sobre uma distinção fundamental dos bichos-de-pena, entre aqueles respectivos ao dia e a noite e, consequentemente, ao dualismo do bem e do mal, o sol e a lua, a vida e a morte.

Outro mito, narrado entre os Kujubim e outros povos da T.I do Guaporé, diz respeito à hierarquia e à escatologia. O mito da origem do gavião real, que, resumidamente, conta a história de um homem que, sendo traído por sua mulher com outro rapaz, fica furioso. Em seu momento de fúria, ele começa a pegar fogo, o que faz com que sua pele se cubra de penas e a textura das cinzas do fogo virem a cor de suas penas, fato que explica os gaviões-reais terem plumagem cinzenta. Nesse processo, seu arco e sua flecha viram, respectivamente, a garra e o bico do gavião. Vingativo, queria matar o homem com quem sua mulher o estava traindo, e para isso ficou na espera em cima de uma árvore por quatro dias. O homem traidor, sabendo das pretensões do gavião, sequer aparecia na aldeia e não saía de dentro de sua casa. Um dia, com uma enorme dor de barriga, colocou somente parte de suas nádegas para fora, o suficiente para que seu ânus ficasse na direção do terreiro fora do perímetro da casa. Esse pequeno descuido foi o suficiente para o gavião agarrá-lo pelas nádegas e levá-lo até o alto daquela árvore onde esperara durante quatro dias. Lá, devorou o traidor e em seguida o defecou, sendo que todas as fezes eliminadas pelo gavião se tornaram os gaviões de outras qualidades, menores e com um potencial de predação relativamente menor.

Em relação ao critério de classificação em torno do tamanho, por exemplo, temos o araçari e o tucano, que para nós são classificados como "espécies" diferentes, mas para os Kujubim são tipos de uma mesma qualidade, já que concebem que o araçari é um tucano imaturo e o mesmo vale para outros tipos de bichos como gaviões. Nessa lógica, portanto, "espécies" diferentes na biologia aparecem como variedades de uma mesma qualidade no pensamento Kujubim. $\mathrm{O}$ aspecto de diferenciação das qualidades de pica-paus (que eles chamam, no português regional, de pinica-paus) se dá por uma questão de originalidade. $\mathrm{O}$ pinica-pau mais comum é, de fato, aquele que é concebido como o original, e outras qualidades menores e de cores diferentes são apenas "cópias malformadas" dessa qualidade principal, espécie de protótipo. Esse critério, aparentemente morfológico, condiz principalmente com a ideia do comportamento. Embora a má-formação se dê pelo traço 
morfológico contrastante (tamanho e cor da plumagem), o que os torna cópia de uma mesma qualidade são os comportamentos, isto é, andar verticalmente em árvores e as pinicarem.

Há casos, também, de bichos-de-pena que transitam entre estatutos ambíguos, como é o caso do pincuã. Pincuãs são conhecidos por sua comunicação interespecífica e por isso são reconhecidos como mensageiros. Dentro da mata, quando alguém está indo caçar e encontra um deles, recebe duas opções, a depender do som que ele emite: "piiincuãã" é o sinal que ele emite dizendo que o humano não vai encontrar nenhuma caça; mas quando ele alegremente canta "titititititi", é sinal de que a caça será farta. Contudo, pincuãs também são bichos-de-pena que podem se transformar em outros bichos, como sapos, e, também, são utilizados por espíritos malignos para se disfarçar no mundo dos vivos, por isso, são também classificados como "seres que se transformam".

Um bicho-de-pena que adquire grande importância na matriz classificatória é a galinha. Diferentemente de diversas etnias ameríndias (VANDER VELDEN 2012), as galinhas, para os povos do Rio Guaporé, não foram trazidas como animais de criações dos brancos. A galinha sempre foi um bicho do mato que vivia na serra. Um dia, um velho Makurap fez tocaia de pegar nambu e logo cedo saiu para a serra. Armou suas armadilhas e seguiu em frente. Quando voltou, havia pegado um casal de galinhas, um macho e outra fêmea. Não reconhecendo aqueles animais, levou-os vivos para a aldeia, na esperança de que alguém pudesse conhecer. Nisso, o dono da galinha apareceu em formato de vento e correu atrás do velho Makurap, que conseguiu fugir e, ao chegar na aldeia, fez um encantamento para aqueles bichos se tornarem de criação, isto é, domésticos para os humanos. Quando estava em Ricardo Franco, havia morrido uma mulher de câncer; eu estava no velório acompanhando os homens, quando eles me disseram: "Eu não sei como é que essa doença ai não, isso não existia pra gente, é coisa nova...as pessoas adoeciam desse jeito não", ao que outro respondeu: "são esses eré aí, contaminam o rio com veneno, só vende comida com câncer"; e outro homem acrescentou: "são essas galinhas aí do eré, esses frango aí que a gente compra na cidade, eles vem com câncer onde já se viu galinha crescer em um mês, me falaram isso lá em Guajará uma vez, são elas que são o câncer”. Deste ponto de vista, galinhas não são animais dos brancos, ou sequer foram introduzidos por eles, mas aquelas que são vendidas por eles o são em formato de doença. Galinhas, portanto, podem ser doenças-de-branco.

Os exemplos são diversos e, infelizmente, não posso descrever todos. Retomemos a pergunta que nos guiou até aqui: seria uma "classificação" um conjunto tão heterogêneo de critérios e relações utilizados para se conceber bichos-de-pena? Dizer que os bichos se coconstiuem, que eles podem ocupar categorias distintas a depender de suas relações, que eles são deuses, doenças de branco e fezes são relações que podem ser condicionadas em "caixinhas", como nos sugerem os "sistemas taxonômicos"?

Não estou certo de que as "classificações" Kujubim são hierárquicas, e, portanto, pragmáticas. Parece-me, antes, que as "classificações" se constituem sob critérios variados, 
sendo eles relacionados uns aos outros. Não são, supostamente, categorias hierárquicas que englobam os bichos-de-pena; são esses que, a depender do critério, podem estar presentes em um ou mais critérios de "classificação", sobretudo porque estão relacionados e as "classificações" (e o conhecimento) são relacionais na medida em que dependem de práticas e do contexto a forma como um bicho é alocado em determinada categoria.

Categorias intelectuais são pensadas através de diversas relações que estão no mundo ou, ainda, de acordo com as posições que elas ocupam no pensamento Kujubim. Como vimos, o conhecimento prático dos Kujubim acerca dos bichos-de-pena é fundamentado a partir da dialética entre aspectos intelectuais no modo como os termos são organizados, e os aspectos práticos, as relações que os seres constituem no mundo. Ao dizer, portanto, que o que existe entre os Kujubim é uma "matriz classificatória", ela implica muito mais na ideia de relação do que na ideia de taxonomia. Relações são fundamentais em três sentidos: o primeiro, é que são relações que constituem um ser (classes de relações); o segundo, via intelecto, constitui relações entre termos e categorias (classes de posições) na medida em que eles estão conectados uns aos outros, como vimos no exemplo do mito dos cujubim; e, por fim, a própria relação entre essas duas classes faz com que categorias e termos sempre se transformem a partir de práticas e vice-versa.

Nesse sentido, há de todo modo em se pensar sobre "classes de posição" (classificação fundada pela posição dos seres num sistema humano de conhecimento) e "classes de relação" (conhecimento relacional porque os seres se relacionam). A relação entre essas duas classes é o que fundamenta a "matriz classificatória" dos Kujubim. Se pudéssemos defini-la, faríamos da seguinte maneira: a relação entre "classes de posições" e "classes de relações" implica em matrizes de atributos, critérios e relações práticas que geram qualidades de seres.

Os Kujubim podem conceber um gavião a partir de algumas "classes de posição" a depender de suas "classes de relações". O gavião-real, por exemplo, é agrupado junto com outros bichos-de-pena nos critérios "tem história", da floresta, do alto, "anda só" e assim por diante. Contudo, essas categorias não precisam necessariamente estarem hierarquizadas umas sob as outras, pois estão, antes, relacionadas. Deste modo, um bicho-de-pena não precisa estar condicionado a uma taxonomia, porque, antes, a partir de diversas relações que estão no mundo e na mente Kujubim, eles ocupam diversos critérios que dependem, portanto, de certa contextualidade e da relação deles com outras qualidades e o próprio ambiente. Neste sentido, um gavião-real pode ser um bicho-de-pena, um marido traído, suas fezes resultam em outros gaviões, ele pode ser do alto, da floresta, predador. Portanto, sempre depende do contexto relacional.

A "matriz classificatória” me parece ser mais abrangente e menos pragmática do que a ideia de taxonomia em si. Afinal, não há uma grade finita de critérios e uma homogeneidade na forma de "classificar": bichos-de-pena nunca são algo, mas sempre estão ou tendem a ser algo na medida em que dependem do critério que está sendo levado em 
conta, de modo que esses critérios também estão relacionados intelectualmente e são pautados em relações diversas no mundo. Classificações hierárquicas são fixas e pragmáticas, "matrizes classificatórias" de critérios variados estão sempre em transformação, em movimento, em relação.

\section{Famílias multiespécies: classificando bichos-de-pena, pensando a si mesmo}

Gostaria agora de chamar a atenção para um aspecto do pensamento Kujubim que se aplica diretamente ao modo como eles concebem os bichos-de-pena, mas que se reflete também, de uma maneira geral, na forma como "classificam" os bichos e, indiretamente, pensam a si mesmos. Certo dia estava acompanhando um trabalho coletivo em uma roça. Elizabeth e Manduca viram um bicho-de-pena e logo me disseram que aquele ser era o bicho do queixada. Depois, eles me disseram que, alguns bichos são acompanhados de bichos-depena. Sendo assim, no barreiro, local de alimentação de diversas qualidades de bicho, se você encontrar uma corujinha-da-noite, com certeza verá também uma anta. Nas capoeiras, se ouvir o barulho da nambu-azul, além de ter o perigo de se confundir com o veado-roxo, você com certeza verá que os dois estarão juntos. Quando eu perguntei os motivos pelos quais essas qualidades andavam juntas e conviviam, eles me disseram que esses seres formavam famílias, que eram parentes e que andavam junto. Nesse sentido, a classificação desses bichos, de uma maneira geral, permite ao pensamento Kujubim, no ato de classificar, extrapolar a classificação de determinada qualidade pensando as qualidades sempre em relação e em conjunto, não isoladamente.

Diferentes qualidades de bichos podem ser classificadas de acordo com características comuns, e principalmente, por serem considerados parentes, tendo em vista que eles convivem na constituição dessas famílias. Quando a classificação de um bicho-de-pena é fundamentada a partir da relação prática e intelectual com outra qualidade de bicho, isso acontece porque, no momento da classificação, fazendo alusões e relações com outras qualidades, o pensamento Kujubim resgata sua gênese enquanto forma de existir e conviver com outras qualidades humanas (as diversas etnias na T.I) e não humanas, de acordo com seu socius aberto para outros seres que estão para além das relações humanas da aldeia.

Sendo assim, a relação intra-humana é também pensada na relação cósmica interespécie, e isso não é algo exclusivo dos povos no Guaporé, como já alertaram Nemo et. al. (2017), pois "o olhar que uma sociedade lança aos seres vivos, é, talvez, largamente inseparável do olhar que ela projeta sobre si mesma" (NEMO et. al. 2017: 316).

Se a socialidade é aberta e estreita as relações entre humanos e não humanos no cosmos, essas relações podem ser nesse caso de constituições classificatórias de famílias e parentes, assim como é nas relações sociais dos humanos nas aldeias. Neste sentido, a cosmologia é plasmada com o modelo sócio-político, e vice-versa, fazendo com que as 
relações humanas da aldeia (vide o compartilhamento de conhecimento, alimentos, objetos materiais) sejam pensadas como as relações do cosmos de uma maneira geral e que, ao mesmo tempo, são incluídas nas classificações desses bichos-de-pena, bichos-de-pelo. Não é que antas e corujas sejam de uma mesma qualidade, mas, como elas fazem família, são "classificadas" juntas; pois a "classificação" é também algo do convívio, do comportamento, das afecções, das práticas e, principalmente, das relações.

\section{Algumas conclusões preliminares}

$\mathrm{O}$ que se pretendeu ao longo desse texto foi o exercício reflexivo de pensar junto e através da "matriz classificatória" dos Kujubim, povo indígena que vive em Rondônia. Contudo, para se chegar na infinidade das classificações é preciso compreender diversos detalhes da vida social desse povo. O primeiro passo é entender que eles vivem em um sistema regional, de seu próprio ponto de vista, onde constantes trocas estão sendo realizadas, principalmente aquelas que dizem respeito aos conhecimentos e as concepções sobre a cultura, história, o mito e o cosmos. Cada etnia da região se reconhece como única e diferentes das outras, mas também reconhecem que, através de seu histórico convívio, eles acabaram por compartilhar diversas concepções sobre a vida, o espaço e os seres humanos e não humanos com quem dividem o mundo.

Neste sentido, eles proporcionam pensar relações com outros seres que não somente os humanos. Para entender as "classificações" Kujubim, é necessário, também, compreender as formas como se sustentam relações com espíritos-donos e domínios da floresta de uma forma geral. A "classificação", que é uma ação eminentemente intelectual, se mostra de certa forma dependente de ações práticas de socialidade com outros seres, que é o que hipoteticamente fundamenta e sustenta essas classificações e, por isso, intelectualismo e empiricismo, intelecto e prática, sentido e materialidade estão em uma relação dialética. Não basta uma metódica observação de costumes e comportamentos dos animais - que, inclusive, é espantosamente detalhada; é preciso conviver com esses animais e compreendê-los para além do que é apenas visto. A relação entre dois tipos de classes fundamenta o modo como um bicho-de-pena é concebido, gerando uma matriz infinita de critérios, categorias e relações. Classificar um bicho-de-pena desta maneira diz respeito também ao modo como os Kujubim classificam o mundo e a si mesmos, e, indo mais a fundo, é possível perceber o quanto suas maneiras de se pensar enquanto organização sociopolítica humana, reflete intensamente na maneira de pensar e classificar os seres dos cosmos, levando em conta a ideia de relação, precisamente porque toda "classificação" é relacional.

Este trabalho, sem dúvidas, pode ser incluído nas definições de etno-ortinologia tendo em vista que ele busca enaltecer diversos aspectos que constituem a disciplina, isto é, "o conjunto de estudos em que se busca compreender as relações cognitivas, comportamentais e simbólicas entre humanos e aves" (FARIAS; ALVES 2007). Note-se, 
todavia, que ele pode ser considerado um estudo em etno-ornitologia desde que assumamos que a nossa ornitologia é também uma etno-ornitologia. Nas cosmologias amazônicas, falar de classificação dos seres vivos ou dos animais não descreve, na realidade, o que é efetivamente classificado. De fato, não é possível apartar os animais e os seres vivos das outras formas existentes. Nesse sentido, nunca se deve presumir o que será o "objeto" da classificação, precisamente porque ele é diferente em sua constituição, em relação ao método utilizado e resultados chegados quando pensado no caso dos Kujubim; o que consideramos (a etno-ornitologia, a ornitologia) como "aves" a partir de uma definição precisa da biologia não corresponde para os Kujubim aos seres muito especiais que rasgam o céu, caçam, pescam, vivem no alto, no baixo, são do rio, da mata, mensageiros, armas de pajé, deuses, donos de formigas e criação da anta, fezes, seres transformacionais e doenças de branco; esses seres são, segundo os Kujubim, os bichos-de-pena.

Por fim, a partir dessa perspectiva, afirmo que em nenhum momento eu etnografei aves. Eu não etnografei seres classificados segundo o modo específico como a ornitologia o faz. O que até agora tenho feito foi etnografar seres que são "classificados" a partir de outras ideias e práticas com e no mundo, que dependem do contexto e de relações para serem classificados: os bichos-de-pena, que podem ser muitas coisas, menos aves. Isso, invariavelmente, implica em pensar que "animais" não só são bons para comer ou se pensar (LÉVI-STRAUSS 2005), ou mesmo se relacionar: eles também são bons enquanto método de pesquisa etnográfica.

\section{Referências Bibliográficas}

ALEIXO, Alexandre. (2007). "Conceitos de espécie e o eterno conflito entre continuidade e operacionalidade: uma proposta de normatização de critérios para o reconhecimento de espécies pelo Comitê Brasileiro de Registros Ornitológicos”. Revista Brasileira de Ornitologia, vol.15, n.2. pp.297-310.

BERLIN, Brent. (1992). Ethnobiological classification: principles of categorization of plants and animals in traditional societies. New York: Princeton University Press.

BEVILAQUA, Ciméia; VANDER VELDEN, Felipe. (orgs). (2016). Parentes, vítimas, sujeitos: perspectivas antropológicas sobre a relação entre humanos e animais. São Carlos: EDUSFCar/ Curitiba: EDUFPR.

CABRAL DE OLIVEIRA, Joana. (2006). Classificação em cena: algumas formas de classificação das plantas cultivadas pelos Wajãpi do Amapari (AP). Dissertação de mestrado. São Paulo: PPGAS/USP.

CARRARA, Eduardo. (1997). Tsi tewara - Um voo sobre o cerrado Xavante. Dissertação de Mestrado. São Paulo: PPGAS/USP. 
DeMELLO, Margo. Animal and society: an introduction to human/animal studies. New York: Columbia University Press, 2012.

DESCOLA, Phillipe. (1986). La selva culta: Simbolismo y praxis en la ecología de los Achuar. Quito: Ed. Abya Yala.

DESCOLA, Phillipe. (1992). "Societies of Nature and Nature of Society”. In: KUPER, Adam. (ed.) Conceptualizing Society. London/New York: Routledge.

DESCOLA, Phillipe. (1998). "Estrutura ou sentimento: a relação com o animal na Amazônia”. Mana, vol.4, n.1.pp.23-45

DESCOLA, Phillipe. (2006). "Beyond Nature and Culture". Proceedings of the British Academy, v.139. pp. 137-155.

DURAN, Iris Rodrigues. (2000). Descrição Fonética e Lexical do Dialeto<Kaw Tayo (Kujubim) da lingua Moré. Dissertação de mestrado. Guajará-Mirim: PPG-Linguística/UFRR.

FARIAS, Gilmar Beserra de; ALVES, Ângelo Chaves. (2007). "Aspectos históricos e conceituais da etnoornitologia”. Biotemas, v. 20, n. 1, p 91-100.

FAUSTO, Carlos. (2008). “Donos demais: Maestria e Domínio na Amazônia”. Mana, vol.14, n.2, p. 329-366.

GALLOIS, Dominique Tilkin (org.). (2005). Redes de relações nas Guianas. São Paulo: Humanitas/FAPESP.

INGOLD, Tim. (1994). Whats is an animal? London: Routledge.

JENSEN, Arthur. (1988). Sistemas indígenas de classificação de aves: aspectos comparativos, ecológicos e evolutivos. Tese de doutorado. Campinas: PPG-Eco/Unicamp.

KIRKSEY, Eben; HELMREICH, Stefan. (2010). "The emergence of multispecies ethnography”. Cultural Anthropology, v. 25, n.4, p. 545-576.

LATOUR, Bruno. (1994). Jamais Fomos Modernos: ensaio de antropologia simétrica. Rio de Janeiro: Editora 34.

LÉVI-STRAUSS, Claude. (2005). O Pensamento Selvagem. Rio de Janeiro: Papirus.

LIMA, Taniza Stolze. (2002). “O que é um corpo?”. Religião e Sociedade, vol.22, n.1, p. 0919.

MALDI, Denise. (1991). "O Complexo Cultural do Marico: Sociedades Indígenas dos Rios Branco, Colorado e Mequens, afluentes do médio Guaporé”. Boletim do Museu Paraense Emílio Goeldi, serie Antropologia, vol.7, n.2

NEMO, François., GRENAND, Françõise, GRENAND, Pierre \& CRISTINOI, Antonia. (2017). "Etnosemântica das classificações animais - exemplos de algumas línguas amazônicas”. In: MARCHAND, Guillaume \& VANDER VELDEN, Felipe (orgs.). Olhares cruzados sobre as relações entre humanos e animais silvestres na Amazônia. Manaus: EDUA.

POSEY, Darrel. (1987). "Introdução”. In: RIBEIRO, Darcy. Suma etnológica brasileira. Edição atualizada do Handbook of South America. Volume 1 - Etnobiologia. Vários autores. Petrópolis: Vozes. 
SOARES-PINTO, Nicole. (2009). Do poder do sangue e da chicha: os Wajuru do Guaporé (Rondônia). Dissertação de mestrado. Curitiba: PPGAS/UFPR.

SOARES-PINTO, Nicole. (2014). Entre as teias do Marico: parentes e pajés djeoromitxi. Tese de doutorado: Brasília: PPGAS/UnB.

VANDER VELDEN, Felipe. (2010) Tupi em Rondônia: diversidade, estado do conhecimento e proposta de investigação. Revista Brasileira de Linguística Antropológica. Vol. 2, n. 1.

VANDER VELDEN, Felipe. (2012). Inquietas Companhias: sobre os animais de criação entre os Karitiana. São Paulo: Alameda.

VANDER VELDEN, Felipe. (2015). “Apresentação ao Dossiê - Animalidades Plurais”. R@u - Revista de Antropologia da UFSCar, vol.7, n.1.

VIVEIROS DE CASTRO, Eduardo. (2002). "Perspectivismo e o Multinaturalismo na América Indígena”. In: A inconstância da alma selvagem e outros ensaios de antropologia. São Paulo: Cosac Naify.

VIVEIROS DE CASTRO, Eduardo. (2004). "Perspectival Anthropology and the Method of Controlled Equivocation”. Tipití vol.2, n.1 p. 3-22.

\section{Gabriel Sanchez}

Graduação em Ciências Sociais e mestre em Antropologia Social (2019), ambos pela Universidade Federal de São Carlos. Atua como membro do Laboratório de Etnologias Transespecíficas (LETS) e é membro do grupo de estudos HUMANIMALIA: Antropologia das relações humanoanimais 